\title{
Editorial: On the Never-Never
}

Is there a game called Botticelli? We think so, and recall it as a game about English poetry, played at English firesides. The first player quotes a line or so-perhaps 'Now no more the juice of Egypt's grape shall moist this lip.' The next player's reply is to quote another line which repeats one of the words of the first offering-e.g. 'It is not now as it hath been of yore'. The effect is to remove the repeated word from the game. The winner of a round is the player whose quotation removes the last remaining word to be banished. The spirit and skill of the game needs a sequence to illustrate it. It is clear from our opening pair of snippets that a common word like 'now' is too lenient to the next player. The rarer the words, the harder the task.

'This makes Shakespeare a plentiful source: 'The multitudinous seas incarnadine, making the green one red'; 'Cribb'd, cabin'd, and confined'. But there are simpler items in the same storehouse. 'If music be the food of love, play on'; 'I am constant as the Northern Star'. 'Then there are the cases where the words are simple and the thought is taxing. Milton's employment of ancient Greek and Latin syntax makes him a good model in this mode: 'Hail holy light, offspring of heaven first born, or of the eternal coeternal stream shall I express thee unblamed?'

Here begins our specimen exchange. It is a duo for simplicity, though the game may be played by any number of players:

A: Give me a beaker full of the warm South.

B: Full fathom five my father lies.

A. My love is like a red red rose.

B. If music be the food of love, play on.

A. Music, when soft voices die, lives in the memory.

B. Death thou must die.

A. Come away, come away death.

B. Nymphs and shepherds, come away. 


\section{Editorial}

Every player but the callow beginner knows of one trap that must be avoided. If your opponent can be induced to quote a line containing never, it is game set and match to you. For you may at once invoke an unstoppable line from King Lear: 'Never, never, never, never, never!' 